\title{
Title: Rapid assessment of Avoidable Blindness and willingness to pay For cataract surgery in tribal region of Surat district of Gujarat
}

state, India.

\section{Abstract (250 words)}

Aim: To estimate prevalence and causes of avoidable blindness among people $\geq 50$ years and to assess willingness to pay (WTP) for cataract surgery in tribal region of south Gujarat, India.

Methods:A cross-sectional population based survey was conducted with 44 randomly selected clusters each having 50 people aged $\geq 50$ years selected by probability proportional to size of sampling. Adults identified with cataract causing visual loss $(<6 / 18)$ in any eye were interviewed to assess their WTP for surgery.

Results: Total of 2137 examined out of 2200 people enumerated (response rate $97.1 \%$ ). The prevalence of blindness (Presenting Visual Acuity (PVA) $<3 / 60$ in better eye) was $2.23 \%$ (95\% Cl: $2.95 \%-1.51 \%)$. Cataract was main cause of blindness $(67.3 \%)$ followed by corneal scarring (8.2\%). Major barrier to cataract surgery cited by bilaterally blind people was lack of escort to the surgical facility (34.3\%). Cataract surgical coverage (CSC) was $84.9 \%$ (eyes) and $92 \%$ (persons). Of the 492 people interviewed to assess WTP for their surgery, only $36.4 \%$ people were willing to pay.

Conclusion: The tribal population has a high poverty profile in India. Within this group cataract remains the main treatable cause of blindness despite a high CSC. Assessment of barriers suggested that a well-coordinated outreach programme with free transport facilities to the surgical facility is required along with strategies to improve accessibility and prioritising cataract blind in the community. One third of people were willing to pay for their surgeries implying that cross subsidization or tier system could be feasible for eye care programme sustainability.

Key words: Blindness, RAAB, Willingness to pay, Tribal, India

\section{Introduction}

South East Asia has the highest burden of blindness where $32 \%$ of the estimated global 39 million blind people live (presenting visual acuity (PVA) $<3 / 60$ in better eye).1,2 Globally it is estimated that $>82 \%$ of all blind people are 50 years and older 2 and that $90 \%$ causes of blindness are avoidable.3 Cataract remains one of the main causes of blindness in the region. Poverty and blindness are closely associated, impacting on accessibility and affordability of eye care services. 4,5 
The latest estimate of prevalence of blindness in India in 2001 was 5.34\% (95\% Cl: $2.1-8.9$ ) (PVA $<3 / 60$ in better eye) among people aged $\geq 50$ years.6,7 Cataract was the main cause of blindness responsible for $62.6 \%$ of the all cases of blindness.6,7Gujarat state is a high performing state as regards to cataract surgical rate (CSR) with over $>10,000$ surgeries/million/year. Despite this CSR, recent survey conducted in 2007in Navsari district of Gujarat found the prevalence of blindness among $\geq 50$ year olds was $4.3 \%$ (PVA $<3 / 60$ in better eye) where cataract constituted approximately $82.6 \%$ of blindness. 8

The tribal belt in India extends from Ambaji till Dharampur bordering Rajasthan, Madhya Pradesh and Maharashtra state. The tribal group (considered the aboriginal population in India) is estimated to be over 104 million in 2011 census.9 Surat district of Gujarat state has a tribal area on its eastern border which extends beyond Mandvi block where $90 \%$ of people are tribal. The tribal community largely comprises of agrarians and landless labourers who survive on meagre resources. Anecdotal reports suggest that these people are poor, illiterate and under privileged. The area lacks basic eye care facilities (there are no dedicated eye care facilities available within the radius of 60 miles of the tribal area of Surat district) which are necessary to achieve the goals envisaged under vision 2020: Right to Sight, Universal health coverage and Universal Eye Health.10

Our newly established charitable tertiary eye care hospital was planning to serve this community through outreach services. For planning purposes there was no data on the magnitude of visual impairment and its causesthis community. To establish a sustainable service we needed to better understand the amount of visual impairment and the willingness of patients within this tribal area, to pay for cataract surgery. This would provide an evidence base to establish practical cost- recovery solutions for a tiered payment system based on affordability (cross-subsidization).

The aim of study was to evaluate magnitude and avoidable causes of blindness and VI in people $\geq 50$ years of age and to determine willingness to pay (WTP) for cataract surgery in a tribal region of Surat district of Gujarat state of India.

\section{Materials and Methods}

Rapid Assessment of Avoidable Blindness (RAAB) is a verified population based survey methodology which targets people $\geq 50$ years.11 This means that smaller sample size is required for a survey (75\% reduction in the population size with just $5 \%$ under-estimation in the actual number of cases in survey area).12 This makes RAAB a very cost effective and time saving tool for assessment of the avoidable blindness.

The study was conducted in 7 tribal sub-districts of Surat district of Gujarat state, India. The total population of this area was $1,070,128$ (2001 census).9

A sample size of 2200 was calculated based on prevalence of $6.9 \%$ (PVA $<6 / 60$ in better eye) among $\geq 50$ population in the survey conducted in Navsari district in 20078 . A total of 44 clusters were selected using a cluster random sampling method and probability proportional to size. A cluster comprise of 50 individuals aged $\geq 50$ years. 
Two survey teams comprising each of; one ophthalmologist for eye examination, two ophthalmic assistants (OAs) (one for acuity testing and one for completion of the questionnaire), one field worker (enumerator) to assist in field work and to locate households, one cluster informer to inform about survey in each selected segment. Training of the two teams was conducted at base hospital. Inter observer variation test was assessed between two teams to get a good agreement (with kappa value $\geq 0.6$ ).

Following standard RAAB methodology, the study was conducted at village level. We had a pilot visit by our field workers who met village head and informed them about survey. He in turn instructed villagers to remain at their homes on the specific date on which the survey to was be conducted in their village. This encouraged a better response rate of the survey. Patients with cataract or any significant eye pathology were referred to the base hospital for free treatment..

Ophthalmic examination was carried out using the established RAAB protocol.12 Furthermore an additional specific questionnaire was designed and incorporated in the standard RAAB form to assess for WTP for surgery. WTP questionnaire was administered to anyone with cataract with PVA $<6 / 18$ in any eye. As the RAAB study design is itself well established and validated, the WTP questionnaire was formulated to ask closed ended questions to minimize inconvenience to the patient.

The WTP questionnaire form had 6 questions which included education level, whether medical treatment for any health reason was sought within the last year, from where (private, government or NGO hospital) and the cost (if it was free or paid from pocket of the patients) for that treatment. WTP for cataract surgery was assessed by firstly confirming their willingness pay or not and if agreeable; how much they were willing to contribute; $\leq 750$ INR $(\$ 13),>750$ INR to $\leq 1500$ INR (\$26) and $>1500$ INR (\$13). The cut off of 750 INR was because the government provided remaining 750 INR to people below poverty line in that year. Prior to administering the questionnaire, each eligible person and their family decision maker were also provided with the following essential information about their condition and the surgical treatment via an interviewer in their local language.

1. Cataract is the cause of their VI.

2. To regain vision only surgical cure is available for cataract.

3. The standard rate for cataract surgery in our hospital is 1500 INR.

4. Your answers on the WTP questions will not affect quality of treatment or price at base hospital in any manner.

Blindness was defined as PVA $<3 / 60$ in the better eye, SVI as PVA $\geq 3 / 60$ to $<6 / 60$ in better eye and $\mathrm{VI}$ as PVA $\geq 6 / 60$ to $<6 / 18$ in better eye. The cataract surgical coverage (CSC) is proportion of cataract surgical need that has been covered (calculated by person and by eyes). ${ }_{13}$ This indicator gives an insight into bilateral and unilateral surgical services already provided.

Ethical approval for this study was obtained from both the London School of Hygiene and Tropical Medicine in London and Tejas Eye Hospital, Mandvi, Surat. The guidelines of Declaration of Helsinki were followed. Informed consent was taken from each study participant and participants who needed treatment were referred to the base hospital.Data analysis was done using automated RAAB software package and that of WTP was done 
using Stata 11 (StataCorp, Texas, USA) statistical analytical software. Univariate risk analysis for factors associated with WTP was performed using odds ratios and (95\%Cl's).

\section{Results}

The study was conducted between 1 and 25 July 2011. It had an overall response rate of $97.1 \%(2137 / 2200)$. Of the 63 non-responders (6 people refused to participate and 57 were not available) 1 was believed to be blind due to cataract. Among the responders 914 were men $(42.8 \%)$. There was no difference in average age of men and women in examined group (Men- 60.4 years versus women- 60.1 years). There was no significant difference in age and sex composition between the sample and entire survey area population.

\section{Prevalence and magnitude of Blindness}

Forty nine people were identified as bilaterally blind, 89 with SVI and 451 with VI.. The age and sex adjusted prevalence of blindness (PVA $<3 / 60$ in better eye) in the entire survey area was $2.2 \%(95 \% \mathrm{CI} 1.5 \%-3.0 \%)$. The adjusted prevalence of SVI (PVA <6/60-3/60) and VI $(<6 / 18-6 / 60)$ was $4.2 \%$ and $21.4 \%$ respectively. The comparisons of results of prevalence of blindness from previous surveys are shown in Table 1.

Table 1 Comparison of Prevalence of blindness in various surveys in India

Prevalence of blindness, SVI and VI increased with age (Table 2). The prevalence of blindness and SVI was higher among women than men [Blindness- OR 2.38 (95\% Cl: 1.15$5.26, p=0.01)$ and SVI- OR $3.53(2.15-5.87), p$ value $<0.001]$.

Table 2 Prevalence of blindness, SVI and VI by age

\section{Causes of blindness}

Overall main in blind persons was cataract (67.3\%, Table 3). For men and women it was $54.5 \%$ and $71.2 \%$ respectively. Corneal scarring accounted for $8 \%$ of blindness. Overall avoidable causes of blindness were responsible for $81.6 \%$ (curable $73.5 \%$, preventable $8.2 \%$ ) of total blindness. Uncorrected aphakia, Glaucoma and ARMD were equally other major causes of blindness (each responsible for $6.1 \%$ of blindness). Posterior segment pathology as a whole was responsible for $18 \%$ of blindness.

Table 3 Main cause of Visual Impairment in the tribal area of Surat, Gujarat, India.

\section{Cataract Surgical Coverage}

597 people were identified to have undergone cataract surgery. The person CSC was $92 \%$ and CSC at the eye level was $84.9 \%$.CSC was higher in men than in women. (Table 4) 
More than half of the operated ( $\mathrm{N}=313,52.40 \%)$ had been operated in charitable hospitals. Private hospitals were important eye care providers ( $N=220,36.9 \%)$. Interestingly, only $10 \%$ $(\mathrm{N}=61)$ surgeries were done in a government establishment and $0.5 \%(\mathrm{~N}=3)$ were operated in eye camp.

\section{Barriers}

Major overall barrier for cataract surgery among bilaterally blind people was "no one to accompany" them to the eye care facility to get operated ( $34.3 \%$ of total).

\section{Willingness to pay (WTP)}

492 people were eligible and all completed the WTP questionnaire. Nearly two thirds $(63.6 \%)$ of the participants were not willing to pay to treat their visually impairing cataract. Demographic characteristics and analysis of data on WTP has been presented in table 5 .

Table 5 Demographic characteristics and analysis of patients with cataract and their willingness to pay for surgery.

There was no difference in WTP by gender but WTP was associated with increased age. Compared to age group 55-59 years, people in $\geq 80$ years had 3 times higher odds to pay. As expected, WTP was strongly associated with literacy and even the just literate had 13.7 times higher odds to pay than illiterate people (95\% Cl: 7.46-26.19, $p=<0.001)$.

Unexpectedly, WTP was lower among blind than VI people. People with blindness and SVI were less willing to pay compared to those with VI. There was no variation in WTP found between unilaterally cataract blind people versus bilaterally cataract blind.

Of the patients that had previous unilateral cataract surgery $53 \%$ were willing to pay for the second eye cataract surgery when they had good post-operative vision (PVA $\geq 6 / 18$ ) compared to $21 \%$ people who had post-operative PVA $<6 / 18$ (OR 4.2, $\mathrm{p}=0.02$ ).

Participants who had sought previous medical services for other conditions in the past year were 2.5 times more likely to pay for cataract surgery compared to those who did not.

Amongst the 179 people that were willing to pay nearly half $(46 \%)$ indicated a willingness to contribute a maximum of 750 INR. Only $13 \%$ were willing to pay over double the amount.

\section{Discussion}

Age and sex adjusted prevalence of blindness in the entire survey area was $2.2 \%(95 \% \mathrm{Cl}$ $1.5 \%-3.0 \%$ ) (PVA <3/60 in better eye). The adjusted prevalence was approximately 3 times higher [3.23\% (95\% Cl: $1.83 \%-5.06 \%$ ] among females compared to males [1.17\% $(95 \% \mathrm{Cl}$ : $0.49 \%-1.85 \%)]$. The prevalence in the survey area was higher compared to other studies 
done in rural states of India but was lower than African countries and China. 14,15,16 In Navsari survey done in tribal areas (2007) the prevalence was $4.3 \%(95 \% \mathrm{Cl}: 3.5-5.1)$ with same definition.8 This high prevalence in Navsari District is due to accessibility of tribal area is less for eye care compared to Surat district. Poverty has been associated with the high prevalence of blindness and this was seen here as well. Aging and gender differences were associated with blindness in this study as in other surveys in India.8,17

The main cause of blindness was cataract $(67.3 \%$ of all causes). This was followed by corneal scars $(8.2 \%)$, glaucoma $(6.1 \%)$ and ARMD (6.1\%). Navsari survey found a higher proportion of cataract as the main cause of blindness (82.6\%).8 Corneal scar was second cause of blindness and men were more affected than women. Traumatic injuries are likely the source and men are exposed as they indulge more in outdoor work in the jungle. Awareness planning regarding ocular protection while at doing agricultural work needs to be developed in the tribal area. Strengthening primary eye care at a local level for ocular trauma and establishing clear referral systems to the base hospital would be beneficial. In addition, this data advocates for the subspecialist corneal services including transplant capability to be provided at the base hospital, if accepted by this specific tribal community.

Refractive Errors (REs) was responsible for $41 \%$ of all causes of VI but was not found to be associated with Blindness or SVI. RE was responsible for $35.4 \%$ of all causes in VI category in Navsari survey in the state and was just preceded by cataract.8 The similar results were found in other studies done in China where RE was the second main cause of blindness after cataract with same definition of blindness.15,18

\section{Cataract surgical coverage}

CSC was also higher in males than females in the study. CSC has been shown to be lower in women in various studies in India, neighbouring countries (Pakistan and Bangladesh) and in other African countries. 19,20,21 This corroborates the fact that women tend to be neglected and have limited decision making roles. They are dependent on their husbands or sons or other family member to make decisions on their behalf. Cataract surgical rate (CSR) of Gujarat state is $>10,000 /$ million/year which is highest in the country but this is uneven in different parts of the state and low in some part including the tribal areas. 22

CSC is considered better indicator than CSR as CSC in conjunction with prevalence of blindness is good indicator for impact of service provision within an eye care programme. CSC for person gives an idea about the proportion of persons with visual loss due to cataract that had accepted cataract surgery and CSC for eyes gives idea on surgical workload for cataract surgeons. 17 The study found that the CSC in tribal area was high (85\% for eyes and $92 \%$ for persons, VA $<3 / 60$ ), suggesting that more unilateral cataract surgical work had taken place. The CSC among people with VA $<6 / 60$ was $72.5 \%$ which was similar to that found in Navsari survey 2006-07 (72.2\%).8 CSC was higher among men than women in keeping with similar studies in India, neighbouring countries (Pakistan and Bangladesh) and in other African countries.19,20,21 However further attention needs to be drawn to the gender inequity and accessibility to eye care.22 The high prevalence of cataract blindness despite a high CSC suggests that surgeries are being performed on visually impaired persons instead prioritising the blind. The major overall barrier to cataract surgery was 'no 
one to accompany them to surgical facility', particularly for women needs to be addressed. Clearly easing accessibility to surgical services needs to be prioritized (e.g. outreach camps closer to patients or provision of transport, key informant support systems reference).

\section{Willingness to Pay}

Only $36.4 \%$ people with visual impairment due to cataract were willing to pay a contribution for the surgery. Although studies on WTP differ from each other employing different methodologies and different sets of questions similar results were noted in Tanzania $40 \%$ people in one region and $36 \%$ in another.23 In Nepal $43 \%$ were willing to pay for the surgery. 24

Despite a high cataract surgical rate (CSR) in the Gujarat state ( $>10,000 /$ million/year, the highest in the country) cataract blindness the remains the major cause of blindness particularly in women. Although no association between WTP and gender was found in this study. The reason for this might be the decision makers in the families are usually males. They usually decide the expenditure including health on behalf of aged people irrespective of their sex. The same results obtained in studies in Tanzania and China.23,25 The evidence suggests that women are disadvantaged as regards to having visually restoring cataract surgery.

Although alternative reasons or barriers such as lack of company to the hospital may be more relevant in women compared to men, it is possible that sensitive questions such as family gender biases in willingness to pay may not be answered accurately to unfamiliar interviewers.

Literate people were more willing to pay than illiterate people (at least can read or write). As in other surveys (China, Bangladesh and Nepal) this finding indicates that educated people have increased financial capacity and may place a higher value on having good vision.24-26 Illiteracy or poor education is clearly associated with blindness and a resignation to "fate".27${ }_{28}$ The Navsari survey showed that illiterate people were 4.5 times more affected than literate people with some formal education.8

Emphasis on improving the quality of surgery is critical for any successful program and the evidence on the importance of the quality of surgery is even clearer when we examine the WTP according to visual outcome of the previous surgery. The people who had good vision (PVA $\geq 6 / 18)$ in their operated one eye were $4.2(95 \% \mathrm{Cl}: 1.02-20.58, \mathrm{p}=0.02)$ times more WTP for other eye cataract surgery than those whose PVA was $<6 / 18$ following cataract surgery. Training of surgeons, good instruments and equipment and regular clinical audits in the hospital must be in place to ensure the quality and long term sustainability. Impact of cataract surgery on poverty reduction has been clearly shown in studies from Kenya.29 Increasing patient awareness about the benefits of regaining sight are likely to influence the reluctance to pay. Further research on such education strategies is required.

Among those who were willing to contribute to their surgery only $46 \%$ were willing to pay the minimum amount of 750 INR. The government provides remaining 750 INR to people below poverty line. It is encouraging to note that over $13 \%$ were willing to pay twice the amount. This information is vital when planning how to introduce cross-subsidization and tier payment system in the hospital.7Several strategies for cost containment and cost recovery have been used successfully across many high volume eye care programmes in India.30-32 
Comprehensive eye care with quality, accessible and affordable to all along with eye care services integrated to health system will help meet the "Universal Eye Health" goal overarching "Universal Health Coverage" goal of WHO.10 To attempt to meet this requirement in this tribal population, we would need to adapt our practice by ensuring regular outreach (screening at village and surgery at base hospital or satellite centre), supported with clear transport options, commonly used in Indian cataract service models. Affordability of services without causing impoverishment can be developed using a cross subsiding system, which in part can be covered as there is willingness to pay by $1 / 3$ of the affected persons in this study, with over $46 \%$ able to cover the minimum of 750 INR. This is a positive starting strategy to be in development of sustainable service within reach of the locality.

In conclusion, the prevalence of blindness is high in the tribal sub-districts of Surat, Gujarat. Cataract remains the main cause of blindness in spite of a high CSC. The majority of surgical service provision ( $>95 \%$ ) was provided in charitable and private facilities. Corneal blindness was next most common cause suggesting an effective health program needs to be in place at all care levels. The findings also suggest that there should be an effective outreach program. Special attention needs to be paid to support and encourage women to take up the surgery and bridge the challenge of "no one to accompany".

Two thirds of people were not willing to pay for their surgery implies that there needs to be a robust cross subsidization or tier system in place to sustain any eye care programme. A significantly increased WTP following a good outcome after their first eye surgery is strong evidence of the importance of continually striving for the best quality in healthcare as an integral part of Universal eye health.

\section{Acknowledgements}

The study was a part of main author's thesis for his course- MSc in Community Eye Healthat London School of Hygiene and Tropical Medicine, London, UK. The study was possible due to collective support for the course from Commonwealth Shared Scholarship Scheme, British Council for the Prevention of Blindness (Boulter fellowship), Sight Savers, Alan and Nesta Fund, International Student House, London School of Hygiene and Tropical Medicine trust fund and Sightsavers. The authors are also grateful to Sarah Pollack, International Centre for Eye health, London and Dr. Praveen Vashist, Department of Community Eye Health, RP Centre, All India Institute of Medical Sciences, New Delhi, India for their expert inputs for the study.

\section{References}

1. World Health Organization, Release of the new global estimates on blindness and visual impairment, 16-02-2011, Available from: http://www.who.int/blindness/en/. [Last accessed July 2016] 
2. Resnikoff S, Pascolini D, Etya'ale D, et al. Global data on visual impairment in the year 2002. Bull World Health Organ 2004;82(11):844-851.

3. Dandona, L., R. Dandona, and R.K. John, Estimation of blindness in India from 2000 through 2020: implications for the blindness control policy. Natl Med J India, 2001. 14(6): p. 32734.17.

4. Gilbert CE, Shah SP, Jadoon MZ, et al. Poverty and blindness in Pakistan: results from the Pakistan national blindness and visual impairment survey. BMJ 2008;336(7634):29-32. doi:10.1136/bmj.39395.500046.AE

5. Dandona, R. and L. Dandona, Socioeconomic status and blindness. Br J Ophthalmol 2001. 85(12): p. $1484-1488$.

6. Bachani, D., G.V. Murthy, and K.S. Gupta, Rapid assessment of cataract blindness in India. Indian J Public Health 2000. 44(3): p. 82-9.

7. National Programme for Control of Blindness, Ministry of Health \& Family Welfare Government of India. Available from:http://mohfw.nic.in/npcbnew/index.asp. [Last accessed March 2020]

8. Murthy GV, Vashist $\mathrm{P}$, John N, et al. Prevelence and causes of visual impairment and blindness in older adults in an area of India with a high cataract surgical rate. Ophthalmic Epidemiol 2010;17(4):185-195. doi:10.3109/09286586.2010.483751.

9. Census office, Registrar General, India., Manual calculation from age group wise census data for the state (rural). 2011. Available from http://www.gujaratstat.com/demographics/7/moreoncensus/12977/stats.aspx. [last accessed July 2016]

10. International Agency for Prevention of Blindness and Vison 2020: The right to sight. Global Action Plan. http://www.iapb.org/advocacy/who-action-plan/UEH.

11. Dineen, B., A. Foster, and H. Faal, A Proposed Rapid Methodology to Assess the Prevalence and Causes of Blindness and Visual Impairment. Ophthalmic Epidemiol 2006. 13(1): p. 31-34.

12. Kuper H, Polack S, Limburg H. Rapid assessment of avoidable blindness. Community Eye Health J 2006;19(60):68-69.

13. Limburg $\mathrm{H}$, Foster A. CATARACT SURGICAL COVERAGE: An indicator to measure the impact of cataract intervention programmes. Community Eye Health J 1998;11(25):3-6. PMID: 17492015; PMCID: PMC1706035.

14. Kalua $\mathrm{K}$, Lindfield $\mathrm{R}$, Mtupanyama $\mathrm{M}$, et al. Findings from a rapid assessment of avoidable blindness (RAAB) in Southern Malawi. PLoS One 2011;6(4):e19226. Published 2011 Apr 25. doi:10.1371/journal.pone.0019226.

15. Li S, Xu J, He M, et al. A survey of blindness and cataract surgery in Doumen County, China. Ophthalmology 1999;106(8):1602-1608. doi:10.1016/S0161-6420(99)90459-1.

16. Wu M, Yip JL, Kuper $H$. Rapid assessment of avoidable blindness in Kunming, china. Ophthalmology 2008;115(6):969-974. doi:10.1016/j.ophtha.2007.08.002. 
17. Nirmalan PK, Padmavathi A, Thulasiraj RD. Sex inequalities in cataract blindness burden and surgical services in south India. $\mathrm{Br} J$ Ophthalmol 2003;87(7):847-849. doi:10.1136/bjo.87.7.847.

18. Li Z, Cui $\mathrm{H}$, Zhang $\mathrm{L}$, et al. Cataract blindness and surgery among the elderly in rural southern Harbin, China. Ophthalmic Epidemiol 2009;16(2):78-83. doi:10.1080/09286580802573193.

19. Jadoon Z, Shah SP, Bourne R, et al. Cataract prevalence, cataract surgical coverage and barriers to uptake of cataract surgical services in Pakistan: the Pakistan National Blindness and Visual Impairment Survey. Br J Ophthalmol 2007;91(10):1269-1273. doi:10.1136/bjo.2006.106914.

20. Wadud Z, Kuper $\mathrm{H}$, Polack $\mathrm{S}$, et al. Rapid assessment of avoidable blindness and needs assessment of cataract surgical services in Satkhira District, Bangladesh. Br J Ophthalmol 2006;90(10):1225-1229. doi:10.1136/bjo.2006.101287.

21. Lewallen S, Mousa A, Bassett $\mathrm{K}$, et al. Cataract surgical coverage remains lower in women. $\mathrm{Br}$ J Ophthalmol 2009;93(3):295-298. doi:10.1136/bjo.2008.140301.

22. Chandrashekhar TS, Bhat HV, Pai RP, et al. Coverage, utilization and barriers to cataract surgical services in rural South India: results from a population-based study. Public Health 2007;121(2):130-136. doi:10.1016/j.puhe.2006.07.027.

23. Lewallen $S$, Geneau $R$, Mahande $M$, et al. Willingness to pay for cataract surgery in two regions of Tanzania. Br J Ophthalmol 2006;90(1):11-13. doi:10.1136/bjo.2005.079715.

24. Shrestha $\mathrm{MK}$, Thakur J, Gurung $\mathrm{CK}$, et al. Willingness to pay for cataract surgery in Kathmandu valley. Br J Ophthalmol 2004;88(3):319-320. doi:10.1136/bjo.2003.026260.

25. He $M$, Chan V, Baruwa $E$, et al. Willingness to pay for cataract surgery in rural Southern China. Ophthalmology 2007;114(3):411-416. doi:10.1016/j.ophtha.2006.09.012

26. Bourne RR, Dineen BP, Ali SM, et al. Outcomes of cataract surgery in Bangladesh: results from a population based nationwide survey. $\mathrm{Br} J$ Ophthalmol 2003;87(7):813-819. doi:10.1136/bjo.87.7.813.

27. Zhao J, Jia L, Sui R, et al. Prevalence of blindness and cataract surgery in Shunyi County, China. Am J Ophthalmol. 1998;126(4):506-514. doi:10.1016/s0002-9394(98)00275-x.

28. Sapkota YD, Pokharel GP, Nirmalan PK, et al. Prevalence of blindness and cataract surgery in Gandaki Zone, Nepal. Br J Ophthalmol. 2006;90(4):411-416. doi:10.1136/bjo.2005.082503

29. Kuper H, Polack S, Mathenge W, et al. Does cataract surgery alleviate poverty? Evidence from a multi-centre intervention study conducted in Kenya, the Philippines and Bangladesh. PLoS One 2010;5(11):e15431. Published 2010 Nov 9. doi:10.1371/journal.pone.0015431.

30. Rao GN. Self sustainability in eye care. Indian J Ophthalmol 1996;44:12933.

31. David W Hutton, Hong-Gam Le, Srinivasan Aravind, et al. The Cost of Cataract Surgery at the Aravind Eye Hospital, India. Invest Ophthalmol Vis Sci 2014;55(13):1289.

doi: https://doi.org/ Vis. Sci. 2014;55(13):1289. 
32. Le HG, Ehrlich JR, Venkatesh R, et al. A Sustainable Model For Delivering High-Quality, Efficient Cataract Surgery In Southern India. Health Aff (Millwood) 2016;35(10):1783-1790. doi:10.1377/hlthaff.2016.0562.

\section{Tables}

\begin{tabular}{ll}
\hline Various Blindness Surveys in the past & Prevalence (PVA $<3 / 60$ in better eye) \\
\hline NPCB $^{*}$ Survey (2001)7 & $5.3 \%(95 \% \mathrm{Cl}: 2.1-8.9)$ \\
Navsari Survey (2007) 8 & $4.3 \%(95 \% \mathrm{Cl}: 3.5-5.1)$ \\
Present Survey (2011) & $2.2 \%(95 \% \mathrm{Cl}: 1.5-3.0)$ \\
\hline
\end{tabular}

Table 1 Comparison of Prevalence of blindness in various surveys in India

*NPCB: National Program for Control of Blindness, India

Table 2 Prevalence of blindness, SVI and VI by age

\begin{tabular}{lrrrrr}
\hline & Blind $\mathbf{n ( \% )}$ & SVI $\mathbf{n}(\%)$ & VI $\mathbf{n}(\%)$ & Normal $\mathbf{n}(\%)$ & Total $\mathbf{n}(\mathbf{1 0 0 \% )}$ \\
\hline $\mathbf{5 0 - 5 4}$ yrs & $2(0.3)$ & $4(0.7)$ & $39(6.6)$ & $546(92.4)$ & $591(100 \%)$ \\
$\mathbf{5 5 - 5 9}$ yrs & $5(0.9)$ & $10(1.9)$ & $87(16.4)$ & $428(80.8)$ & $530(100 \%)$ \\
$\mathbf{6 0 - 6 4}$ yrs & $5(1.3)$ & $15(3.8)$ & $102(25.6)$ & $276(69.3)$ & $398(100 \%)$ \\
$\mathbf{6 5 - 6 9}$ yrs & $4(1.6)$ & $19(7.8)$ & $75(30.6)$ & $147(60.0)$ & $245(100 \%)$ \\
$\mathbf{7 0 - 7 4}$ yrs & $11(6.1)$ & $21(11.6)$ & $69(38.1)$ & $80(44.2)$ & $181(100 \%)$ \\
$\mathbf{7 5 - 7 9}$ yrs & $5(5.0)$ & $15(15.0)$ & $43(43.0)$ & $37(37.0)$ & $100(100 \%)$ \\
$\mathbf{8 0 + y r s}$ & $17(18.5)$ & $5(5.4)$ & $36(39.1)$ & $34(37.0)$ & $92(100 \%)$ \\
\hline
\end{tabular}


Table 3 Main cause of Visual Impairment in the tribal area of Surat, Gujarat, India.

\begin{tabular}{|c|c|c|c|}
\hline & Blind & SVI & VI \\
\hline & n (\%) & n (\%) & n (\%) \\
\hline Refractive error & 0 & 0 & $185(41 \%)$ \\
\hline Cataract, untreated & $33(67.3 \%)$ & $74(83.1 \%)$ & $234(51.9 \%)$ \\
\hline Aphakia, untreated & $3(6.1 \%)$ & $3(3.4 \%)$ & $2(0.4 \%)$ \\
\hline Total curable & $36(73.5 \%)$ & $77(86.5 \%)$ & $421(93.3 \%)$ \\
\hline Surgical complications & 0 & $2(2.2 \%)$ & $8(1.8 \%)$ \\
\hline Phthisis & 0 & 0 & 0 \\
\hline Other corneal scar* & $4(8.2 \%)$ & $1(1.1 \%)$ & $1(0.2 \%)$ \\
\hline Total preventable & $4(8.2 \%)$ & $3(3 \%)$ & $9(2.0 \%)$ \\
\hline Total avoidable & $40(81.6 \%)$ & $80(89.9 \%)$ & $430(95.3 \%)$ \\
\hline Glaucoma & $3(6.1 \%)$ & $3(3.4 \%)$ & $3(0.7 \%)$ \\
\hline Diabetic retinopathy & 0 & 0 & $3(0.7 \%)$ \\
\hline Potentially preventable & $3(6.1 \%)$ & $3(3.4 \%)$ & $6(1.3 \%)$ \\
\hline Globe abnormality ${ }^{\star *}$ & $1(2 \%)$ & 0 & 0 \\
\hline ARMD & $3(6.1 \%)$ & $3(3.4 \%)$ & $9(2.0 \%)$ \\
\hline $\begin{array}{l}\text { Other post. segment / } \\
\text { CNS }{ }^{\text {a }}\end{array}$ & $2(4.1 \%)$ & $3(3.4 \%)$ & $6(1.3 \%)$ \\
\hline Total posterior segment & $9(18.4 \%)$ & $9(10.1 \%)$ & $21(4.7 \%)$ \\
\hline Grand total & 49 & 89 & 451 \\
\hline
\end{tabular}

* Other corneal scars- leucoma, staphyloma, apparent corneal opacity centered over pupil

** Globe abnormality includes microphthalmos, anophthalmos, staphyloma and enucleated eyes.

a Other post. seg. /CNS- If VA $<6 / 18$ not attributed to other causes but a specific cause identified.

Table 4 Cataract Surgical Coverage (CSC), (eye and person)with PVA

\begin{tabular}{lllllll}
\hline \multicolumn{3}{l}{ Eyes (\%) } & \multicolumn{4}{l}{ Persons (\%) } \\
\hline & Male & Female & Total & Male & Female & Total \\
\hline VA $<3 / 60$ & 89 & 82.2 & $\mathbf{8 4 . 9}$ & 95.7 & 89.6 & $\mathbf{9 2}$ \\
\hline VA $<6 / 60$ & 77.7 & 69.1 & $\mathbf{7 2 . 5}$ & 88.4 & 79.2 & $\mathbf{8 2 . 7}$ \\
\hline VA $<6 / 18$ & 48.1 & 42.1 & $\mathbf{4 4 . 5}$ & 60.1 & 51.6 & $\mathbf{5 4 . 9}$ \\
\hline
\end{tabular}


Table 5 Demographic characteristics and analysis of patients with cataract and their willingness to pay for surgery.

\begin{tabular}{|c|c|c|c|c|c|}
\hline Age (years) & Willing & Willing \% & Total & Odds ratio $(95 \% \mathrm{Cl})$ & $P$ value \\
\hline $50-59$ & 26 & $24.1 \%$ & 108 & Reference & \\
\hline $60-69$ & 73 & $36.3 \%$ & 201 & $1.8(1.03-3.2)$ & 0.028 \\
\hline $70-79$ & 61 & $42.4 \%$ & 144 & $2.32(1.29-4.2)$ & 0.003 \\
\hline $80+$ & 19 & $48.7 \%$ & 39 & 3.0(1.29-6.9) & 0.004 \\
\hline Total & 179 & $36.4 \%$ & 492 & & \\
\hline \multicolumn{6}{|l|}{ Sex } \\
\hline Male & 70 & $35.7 \%$ & 196 & Reference & \\
\hline Female & 109 & $36.8 \%$ & 296 & $1.05(0.71-1.55)$ & 0.80 \\
\hline \multicolumn{6}{|l|}{ Education } \\
\hline Illiterate & 103 & $25.7 \%$ & 400 & Reference & \\
\hline $\begin{array}{l}\text { Literate } \\
\text { Just literate }\end{array}$ & 76 & $82.6 \%$ & 92 & 13.7(7.46-26.19) & $<0.001$ \\
\hline (Informal education - who can read or write) & 17 & $80.9 \%$ & 21 & $12.25(3.85-50.86)$ & $<0.001$ \\
\hline Primary & 36 & $76.6 \%$ & 47 & $9.44(4.47-21.21)$ & $<0.001$ \\
\hline Secondary & 17 & $94.4 \%$ & 18 & 49.01(7.43-2054.8) & $<0.001$ \\
\hline Higher secondary & 6 & $100 \%$ & 6 & & \\
\hline \multicolumn{6}{|l|}{ Visual acuity } \\
\hline $\mathrm{VI}$ & 42 & $48.3 \%$ & 87 & Reference & \\
\hline SVI & 100 & $34.7 \%$ & 288 & $0.57(0.34-0.95)$ & 0.02 \\
\hline Blind & 31 & $26.5 \%$ & 117 & $0.39(0.21-0.72)$ & 0.001 \\
\hline \multicolumn{6}{|l|}{ Cataract blind } \\
\hline Unilateral blind due to cataract & 148 & $37.4 \%$ & 396 & Reference & \\
\hline Bilateral blind due to cataract & 31 & $32.3 \%$ & 96 & $0.8(0.48-1.31)$ & 0.35 \\
\hline \multicolumn{6}{|l|}{ Operation status of other eye } \\
\hline Operated & 139 & $34.6 \%$ & 401 & Reference & \\
\hline Not operated & 40 & $43.9 \%$ & 91 & $1.48(0.9-2.4)$ & 0.09 \\
\hline \multicolumn{6}{|l|}{ Cataract blindness by laterality } \\
\hline One eye Operated, other cataract blind & 3 & $14.3 \%$ & 21 & Reference & \\
\hline Both eyes cataract blind & 11 & $36.6 \%$ & 30 & $3.47(0.73-22.03)$ & 0.07 \\
\hline \multicolumn{6}{|l|}{ Outcome after other eye cataract surgery } \\
\hline$<6 / 18$ & 4 & $21.1 \%$ & 19 & Reference & \\
\hline$\geq 6 / 18$ & 18 & $52.9 \%$ & 34 & $4.21(1.02-20.58)$ & 0.02 \\
\hline \multicolumn{6}{|l|}{ Medical treatment sought within last year } \\
\hline No & 153 & $34.3 \%$ & 446 & Reference & \\
\hline Yes & 26 & $56.5 \%$ & 46 & $2.5(1.3-4.9)$ & 0.003 \\
\hline \multicolumn{6}{|l|}{ Satisfaction with cataract surgery } \\
\hline Dissatisfied+ indifferent to outcome & 1 & $20 \%$ & 5 & Reference & \\
\hline Satisfied & 17 & $51.5 \%$ & 33 & $4.25(0.35-221.3)$ & 0.18 \\
\hline
\end{tabular}

